\title{
Evaluation of Traditional "Micro Catchment Management" Practices in Respect with Basic Concepts of Modern Water Resources Management
}

\author{
Udayanga N.W.B.A.L. and Najim M.M.M. ${ }^{*}$ \\ Department of Zoology, Faculty of Science, University of Kelaniya, Kelaniya, Sri Lanka \\ mnajim@kln.ac.lk
}

\begin{abstract}
Sri Lanka has beenconsidered as one of the agricultural countries that had maintained sustainable hydraulic and agricultural production system since the early civilizations. Various varieties of paddy have been the dominant among theagricultural crops. Well planned management of water resources is one of the key requirementsto obtain high yields, since the water requirement of paddy is relatively high. Thus traditional concepts and methods have been developed, to ensure the sustainable and optimum management of water resources especially within the dry and intermediate zones.The storage,conservation and the sustainable usage of water has been practiced traditionally since the precipitation is limited temporally and spatially.Specified approaches known as Micro Catchment Management (MCM) have been practiced to prevent and cope with water scarcity. Thus the ancient concepts of MCM is studied and evaluated on a scientific basis along with the modern concepts of water resources management, to identify the eco-consciousness of the ancient practices. Different practices onMCM were gathered from literary sources such as ancient manuscripts, palm leave books, publications and were verified through oral interviews with experienced traditional practitioners of the discipline of VasthuShastra. The verified concepts were scientifically evaluated and were compared with the basic concepts of modern water resources management. In this approach, localities have been identified and managed as separate entities due to which the term MCM has been referred to.With the identification of such boundaries of land that defines the catchment area, all the available water resources were identified and sustainably managed to minimize any losses of water without optimal use. The surface water flows of the area were often diverted to nourish tanks, allowing a sufficient ecological flow downstream. Thus, different practiceshave been followed in the ancient times such as specific land selections, diversion practices, dam and tank constructions, specific techniques to store water, minimize water infiltration and seepage, minimize evaporation and wind action, etc..Importance of establishing and maintaining patches of forest within the catchment areas, the ecofriendly methods of forestestablishment and management, specific tree species that should be grown are also stated. Thus, the key practices of traditional MCM facilitate the ecofriendly sustainable utilisation and management of water resources in harmony with the environment.
\end{abstract}

Keywords: Traditional, Sustainable, Water resources, Eco-conscious, Ecological flow, Micro catchment management 